\title{
Protoporphyrin Measurement
}

National Cancer Institute

\section{Source}

National Cancer Institute. Protoporphyrin Measurement. NCI Thesaurus. Code C146998.

The determination of the amount of protoporphyrin present in a sample. 